\title{
论文
}

\section{青藏高原东南缘地壳上地幔三维S波速度结构及 动力学意义}

\author{
张智奇 ${ }^{1}$, 姚华建 ${ }^{1,2,3^{*}}$, 杨妍 $^{1}$
}

1. 中国科学技术大学地球和空间科学学院地震与地球内部物理实验室, 合肥 230026 ;

2. 蒙城地球物理国家野外科学观测研究站, 蒙城 233500 ;

3. 中国科学院比较行星学卓越创新中心, 合肥 230026

* 通讯作者, E-mail: hjyao@ustc.edu.cn

收稿日期: 2020-01-22; 收修改稿日期：2020-04-20; 接受日期：2020-04-30; 网络版发表日期：2020-06-23

科技部国家重点研发计划项目(编号: 2018YFC1503400)和中国地震科学实验场项目(编号: 2018CSES0101)资助

摘要 青藏高原东南缘地形地貌复杂, 构造运动强烈, 是研究青藏高原地下变形和物质运移的重点区域. 文章通 过该区域132个固定台站的10年地震瑞利面波的双台法频散分析，并融合背景噪声方法的面波频散数据，获得了 周期为 5 150s 的瑞利面波相速度频散资料, 然后使用面波直接反演方法得到了该区域从地壳到上地幔顶部的三 维 $\mathrm{S}$ 波速度结构模型。观测到该区域中下地壳存在两条低速带, 分别分布在松潘-甘孜块体与川滇菱形块体西北部 地区，以及小江断裂带及其东侧的云贵高原地区。小江断裂带及东侧的低速体很可能是其地壳本身增厚导致了壳 内长英质物质发生塑性变形甚至部分熔融而造成的。此外，该区域中下地壳呈现显著的正径向各向异性 $\left(V_{\mathrm{SH}}>V_{\mathrm{SV}}\right)$ 也增强了 $V_{\mathrm{SV}}$ 结构的低速异常幅度。小江断裂带的壳内低速异常体向南跨过红河断裂带延伸到越南北 部, 其形成可能与上地幔热源密切相关. 两条壳内低速带在安宁河-则木河断裂带附近被一个高速体所隔开, 其正 好位于峨眉山大火成岩省的内带和中带区域。在云南中部峨眉山大火成岩省内带地壳中观测到了一个非常明显 的柱状高速体, 可能是峨眉山大火成岩省形成时残留在地壳中的基性-超基性物质. 在上地幔顶部, 红河断裂以南 的印支和华南块体中出现了大范围的低速异常，并随着深度增加逐渐沿着小江断裂带向北延伸进入扬子克拉通. 基于成像结果，认为青藏高原东南缘正同时经历三种不同模式的构造运动：(1) 上地壳物质强度较大，在大型走 滑断层的控制下呈刚性挤出; (2) 中下地壳存在被较高强度物质分隔开的两片黏塑性物质区域，在区域应力场和 断裂带的控制下向南发生塑性运移; (3) 红河断裂以南的上地幔主要受控于大规模的软流圈物质上涌, 与岩石圈 拆沉和缅甸下方印度板块的东向俯冲与后撤密切相关.

关键词 青藏高原东南缘, 面波层析成像, 地壳上地幔 $\mathrm{S}$ 波速度结构, 小江断裂带, 峨眉山大火成岩省, 软流圈上涌

\section{1 引言}

青藏高原是在约 $50 \mathrm{Ma}$ 之前由欧亚板块和印度板
块陆陆碰撞形成的世界上最高的高原(Molnar和Tapponnier, 1975; Rowley, 1996), 碰撞所造成的强烈地形 隆升，复杂的地下结构和物质形变以及剧烈碰撞缩短

\footnotetext{
中文引用格式: 张智奇, 姚华建, 杨妍. 2020. 青藏高原东南缘地壳上地幔三维S波速度结构及动力学意义. 中国科学: 地球科学, 50: 1242-1258, doi: 10.1360 SSTe-2020-0016

英文引用格式: Zhang Z, Yao H, Yang Y. 2020. Shear wave velocity structure of the crust and upper mantle in Southeastern Tibet and its geodynamic implications. Science China Earth Sciences, 63: 1278-1293, https://doi.org/10.1007/s11430-020-9625-3
} 
后大量青藏高原岩石圈物质的去向一直是学界研究的 热点. 青藏高原地质演化过程目前主要有两种端元模 型：一种是刚体块体挤出模型，其认为青藏高原岩石 圈物质沿着某些主要的走滑断层从高原中部被挤出, 地壳上地幔形变耦合(Tapponnier等, 1982, 2001); 另一 种是地壳通道流模型，其认为在中下地壳存在一个低 黏度通道，地壳物质通过该通道可以更有效的从青藏 高原中部运移到青藏高原东南缘, 且地壳上地幔变形 是解耦的(Royden等，1997，2008; Clark和Royden, 2000; Beaumont等，2001). 作为青藏高原物质挤出的 重要通道之一, 青藏高原东南缘(主要包括川滇地区) 是检验这两种端元模型正确性的绝佳区域.

不同于处于碰撞中心区域的青藏高原南缘，青藏 高原东南缘的地形是平缓变化的，且缺乏大尺度的新 生地壳缩短(Royden等, 1997). 该区域主要由走滑断层 所主导, 如鲜水河-小江断裂带和红河断裂带, 另外还 存在一些复杂的走滑加正断型的断裂带, 如大理断裂 带(Royden等, 1997; Burchfiel和Chen, 2012), 而以这三 个断裂带为边界的菱形地块被称为川滇菱形块体 (Kan 等, 1977; Wang等, 1998). 大量的大地测量学结果都表 明该区域的地壳运动主要是呈现顺时针旋转的模式 (图1中蓝色箭头)(King等，1997; Chen等, 2000; Zhang 等，2004)，这也进一步表明青藏高原的物质在向东南 运移.

近些年来，随着地震台站的增加、观测数据的积 累以及反演方法的进步，我们得到了青藏高原东南缘 地区越来越精细的岩石圈结构模型. 接收函数结果表 明青藏高原东南缘地区的Moho深度变化巨大, 川西高 原的地壳厚度高达60 70km, 而云南南部的地壳厚度 只有30 40km(He等, 2014; Wang等, 2017), 并且其下 方的岩石圈也出现了一定程度的减薄 $(\mathrm{Hu}$ 等, 2011, 2012; Yang等，2017), 不过四川盆地下方依然保持着 较厚的岩石圈(张耀阳等, 2018). 大量面波和体波走时 成像结果以及大地电磁成像结果都在该区域的中下地 壳中观测到了低速带(Yao等, 2010; Yao, 2012; Bao等, 2015; Han等, 2017; Peng等, 2017; Fu等, 2017, 2018; Hu 等, 2018; Qiao等, 2018)或高导层(孙洁等, 2003; Bai等, 2010; Li等, 2019). Bai等(2010)的大地电磁成像结果观 测到东西两个高导层, 西侧的高导层位于东喜马拉雅 构造结附近，而东侧的高导层基本上是沿着鲜水河-小 江断裂带一直向南延伸. Bao等(2015)的瑞利面波和接

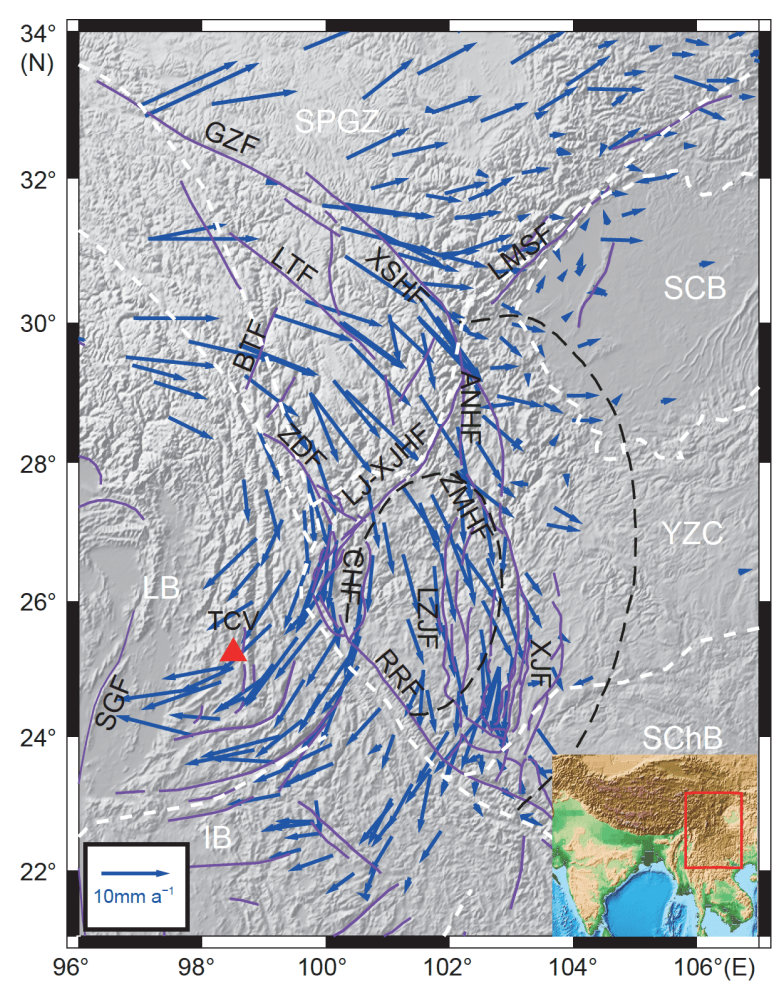

图 1 研究区域的地质构造及地表GPS速度场

紫色实线为断层: GZF, 甘孜断裂; LTF, 理塘断裂; XSHF, 鲜水河断 裂带; LMSF, 龙门山断裂带; BTF, 巴塘断裂; ZDF, 中甸断裂; ANHF, 安宁河断裂带; LJ-XJHF, 丽江-小金河断裂带; ZMHF, 则木河断裂 带; CHF, 程海断裂; LZJF, 绿汁江断裂; SGF, 实皆断裂; RRF, 红河断 裂带; XJF, 小江断裂带. 白色虚线为块体边界: SPGZ, 松潘-甘孜块 体; $\mathrm{SCB}$, 四川盆地; $\mathrm{LB}$, 拉萨块体; YZC, 扬子克拉通; $\mathrm{SChB}$, 华南块 体; IB, 印支块体. 蓝色箭头为Zhang等(2004)使用GPS得到的相对于 稳定的欧亚板块的地表速度场; 红色三角为腾冲火山(TCV), 黑色虚 线为峨眉山大火成岩省的内带和中带 $(\mathrm{Xu}$ 等, 2004), 插图为研究区 域所在位置

收函数联合反演结果同样观测到在中下地壳 $(20$ $30 \mathrm{~km}$ 深度)存在着两条低速带, 西侧的低速带从川滇 菱形块体的北部向南跨过金沙江-红河断裂带延伸到 滇缅泰块体中, 而东侧的低速带从川滇菱形块体的东 南部向南穿过红河断裂带延伸到印支块体中. 虽然不 同学者观测到的低速带的形态和结构存在一定的差 异，但是其空间分布均与该区域的主要走滑断层之间 存在较好的关联. 不过受限于观测方法和台站分布范 围, 前人的研究结果并未能很好的检验这两条低速带 之间的连通性. 面波方位各向异性给出的快波方向与 低速带的延伸方向也较为一致(Yao等, 2010; 王琼等, 2015; Chen等, 2016; Liu等, 2019), 不过与体波成像结 
果(Wei等, 2013)在研究区域南部存在一定的差异, 在 上地幔顶部体波给出的快波方向近似为东西向, 而面 波给出的快波方向为北西-南东向.

大量地球物理研究在云南中部及周边地区(例如 攀枝花地区附近)观测到了高速异常(刘建华等, 2000; Yao等, 2008; 徐涛等, 2015; 郑晨等, 2016; Qiao等, 2018)、较高的正剩余重力异常(Deng等, 2014, 2016)、较强的负径向各向异性(Huang等, 2010)以及 Moho面上隆等现象(Yang等，2020), 可能与峨眉山大 火成岩省有关. 另外体波的深部成像结果显示在华南 块体以及印支块体下方存在大范围的上地幔低速异常 (Li等, 2008; Huang等, 2015; Lei和Zhao, 2016), 可能与 软流圈物质上涌有关. 这种软流圈物质上涌与印度板 块在缅甸弧下方深俯冲至地幔转换带、并在地幔转换 带内运移至小江断裂带造成高速板块滞留脱水等过程 形成的“大地幔楔”结构与动力学过程密切相关(Lei等, 2009, 2019; Lei和Zhao, 2016).

基于以上的研究结果, 目前学界已普遍接受在青 藏高原东南缘存在低速且高导的中下地壳. 不过对于 其是否可以证明在青藏高原东南缘下方存在毫无阻 挡的大尺度水平地壳流仍存在争议. 虽然地震学和大 地电磁的结果较为相似, 但是由于这些方法的分辨率 限制, 其垂向和水平范围的低速(或高导)区域依然是 不精确的. 另外, 峨眉山大火成岩省以及东向俯冲的 印度板块对青藏高原东南缘地壳上地幔速度结构和 物质运移的影响虽有一些研究(Lei等, 2019; Yang等, 2020), 但还有待更进一步的研究, 因此对于该区域地 壳上地幔结构进行更精细的成像研究是十分有必 要的.

本研究使用了布设在青藏高原东南缘的 132 个省 级固定台站，处理了这些台站记录的自2007年至2017 年间的地震面波数据, 获得了可靠且路径覆盖密集的 中长周期瑞利面波双台相速度频散资料, 并融合了在 该区域利用噪声互相关提取的中短周期瑞利面波频散 数据(Yang等, 2020), 最终得到了周期范围在 5 150s的 瑞利面波频散数据, 采用面波直接反演方法(Fang等, 2015)得到青藏高原东南缘较精细的地壳上地幔三维S 波速度结构模型. 结合前人的地质以及地球物理观测 结果, 详细讨论了青藏高原东南缘中下地壳两条低速 带的连通性以及成因, 峨眉山大火成岩省对中下地壳 低速带的阻隔, 以及印支块体和华南块体下方地幔岩
石圈拆沉和软流圈物质上涌这三个科学问题.

\section{2 数据和方法}

\section{1 频散处理}

本次研究中所使用的地震面波数据来自于布设在 该区域的132个宽频带长周期固定地震台站(图2a), 使 用了 2007 年7月至 2017 年7月总计约 10 年的数据(国家 测震台网数据备份中心(郑秀芬等, 2009; Zheng等, 2010)), 总共有3687个远震事件. 事件的笁选准则是: (1) 地震震级为 $M_{\mathrm{w}} 5.5 \sim 7.2$; (2) 地震到两个台站之间的 最小距离大于 $1000 \mathrm{~km}$; (3) 地震与两个地震台站之间 的大圆路径距离之差要大于 $50 \mathrm{~km}$ 且基本位于同一大 圆路径上(Yao等, 2006). 笁选后实际使用的地震事件 仍然有 3618 个且事件的方位分布是较为均匀的(图2b).

我们采用基于图像分析的双台面波相速度频散曲 线自动提取方法(姚华建等, 2004)自动提取出周期范 围在15 150s的瑞利波相速度频散曲线, 总计451921 条. 为了去除自动提取中一些可能存在的问题, 对自 动提取出的频散曲线进行了质量控制(如网络版附图1 所示, http://earthen.scichina.com), 去除了一些周期范 围过短或斜率过大的数据, 并进行了路径集群分析 (Zhang等, 2018) 以去除一些错误的频散数据. 在对十 年的数据进行平均后我们最终得到了非常可靠的频散 数据. 大部分台站对能提取出的频散曲线至少有几十 条(图3a), 部分台站对甚至能提取出 300 多条频散曲线. 经过笁选和相同台站对频散曲线的平均, 最终得到了 3939条瑞利波双台间的平均相速度频散曲线.

我们得到的频散曲线的最短周期为 $15 \mathrm{~s}$, 其对应的 敏感深度主要是中地壳. 为了反演得到可靠的地壳到 上地幔深度范围的S波速度结构, 加入Yang等(2020)在 该区域通过背景噪声互相关方法提取到的 5 40s 周期 的 6589 条频散数据. 对于这两种数据重叠的周期区间 (15 40s), 比较了这两种数据之间的差别(图4), 两者 之间的偏差基本上是呈正态分布, 均值非常接近零, 标准差也只在0.05 0.065 $\mathrm{km} \mathrm{s}^{-1}$, 说明通过两种方法提 取的频散曲线数据是自洽的, 因此我们采用Yao等 (2008) 提出的方法将两者重叠部分的数据进行了平 均, 最终获得了 7441 条频散数据. 图3b展示了各周期 的路径数统计, 可以看出即使在中长周期 $(>50 \mathrm{~s})$ 依然 有较多的路径数 $(>2000)$, 而中短周期 $(\leq 50 \mathrm{~s})$ 由于加入 
(a) $34^{\circ}$

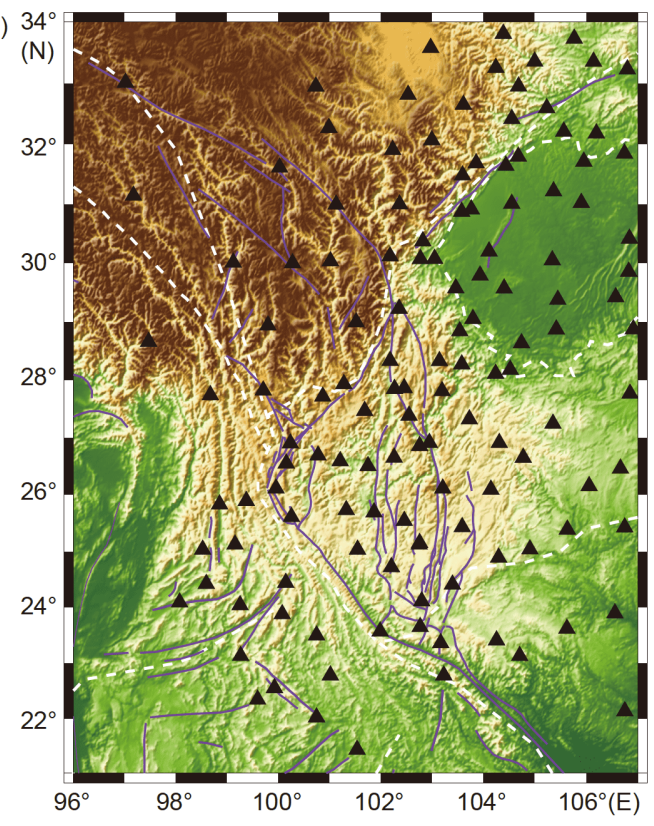

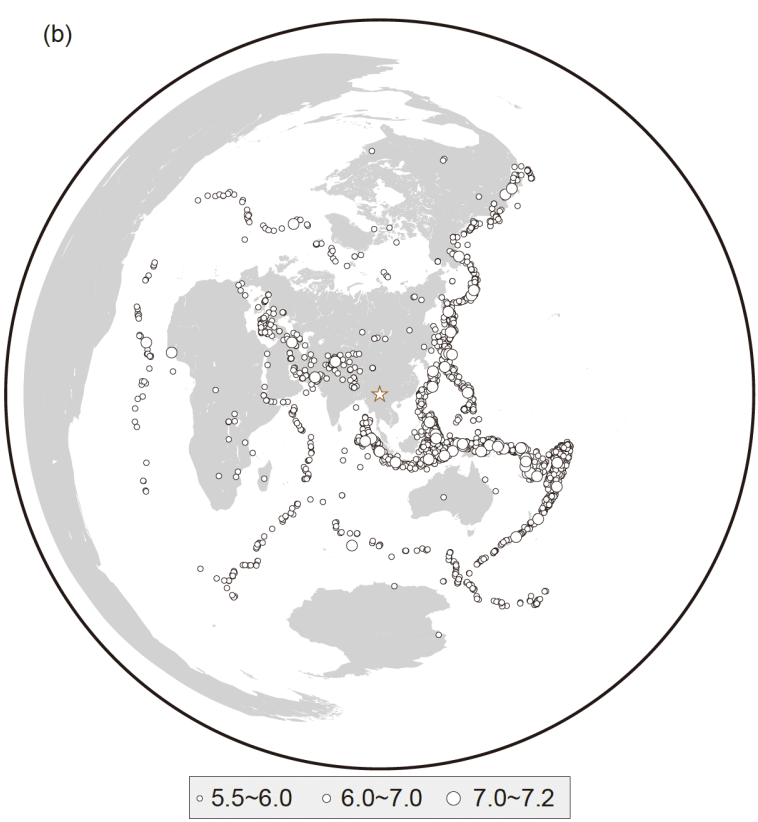

图 2 研究区域台站(a)与所使用的地震事件(b)分布图

(a) 黑色三角形代表地震台站, 紫色实线为断层, 白色虚线为块体边界, 同图1; (b) 圆圈代表地震事件, 红色五角星表示研究区域
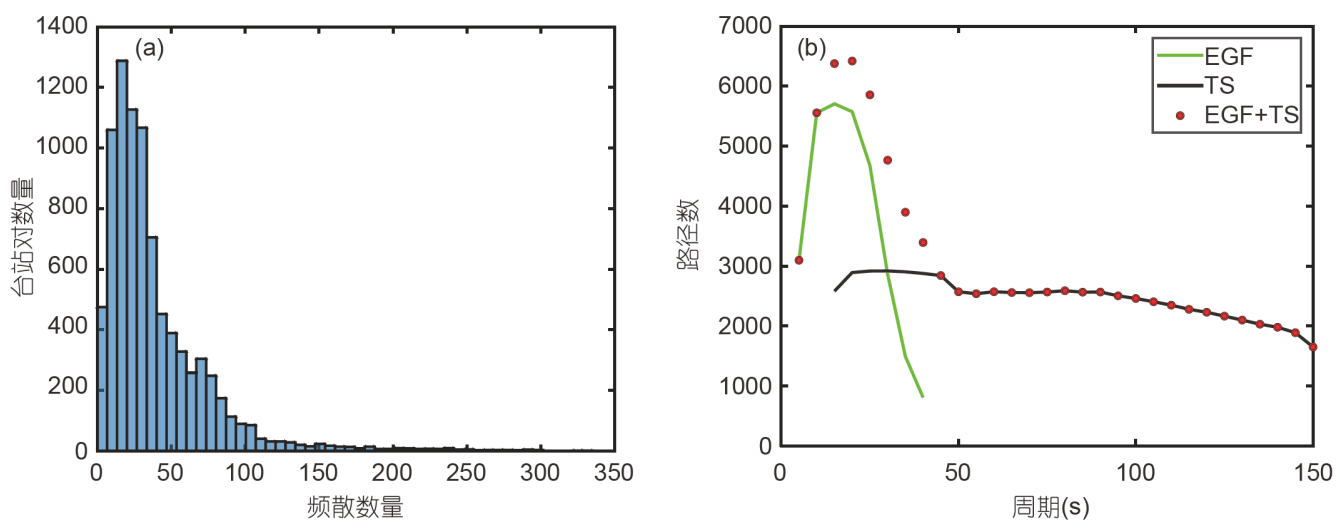

图 3 同一台站对提取得到的频散曲线数量(a)和各周期最终得到的双台路径数(b)分布图

(b)中EGF为背景噪声路径数, TS 为双台法路径数, EGF+TS为两者合并后的路径数

了背景噪声数据使得路径数有了很大的提升 $(>4000)$. 由图 5 可以看出在四个周期(15、50、100和120s)下研 究区域内部的路径方位覆盖都是十分好的.

\section{2 面波直接反演方法}

本次反演使用的是Fang等(2015)发展的面波直接 反演方法, 可以直接从不同周期不同路径的面波频散 走时直接反演获得三维 $\mathrm{S}$ 波速度结构, 从而避免了传 统的面波成像中需要将面波相速度或群速度混合路径
频散反演到二维相速度或群速度分布图这一中间步 骤. 该方法的面波走时正演计算采用的是Rawlinson和 Sambridge(2005)提出的基于快速行进法的射线追踪方 法，从而可以考虑在复杂速度结构下不同周期面波的 非大圆路径传播效应，因此对于传播路径复杂的短周 期面波，该方法可以有效地提升反演准确度. 面波直 接反演方法相对间接的两步反演方法(例如Yao等, 2008)主要有以下三点优势(Fang等, 2015): (1) 不需要 构建二维的相速度或群速度图; (2) S波速度结构两步 

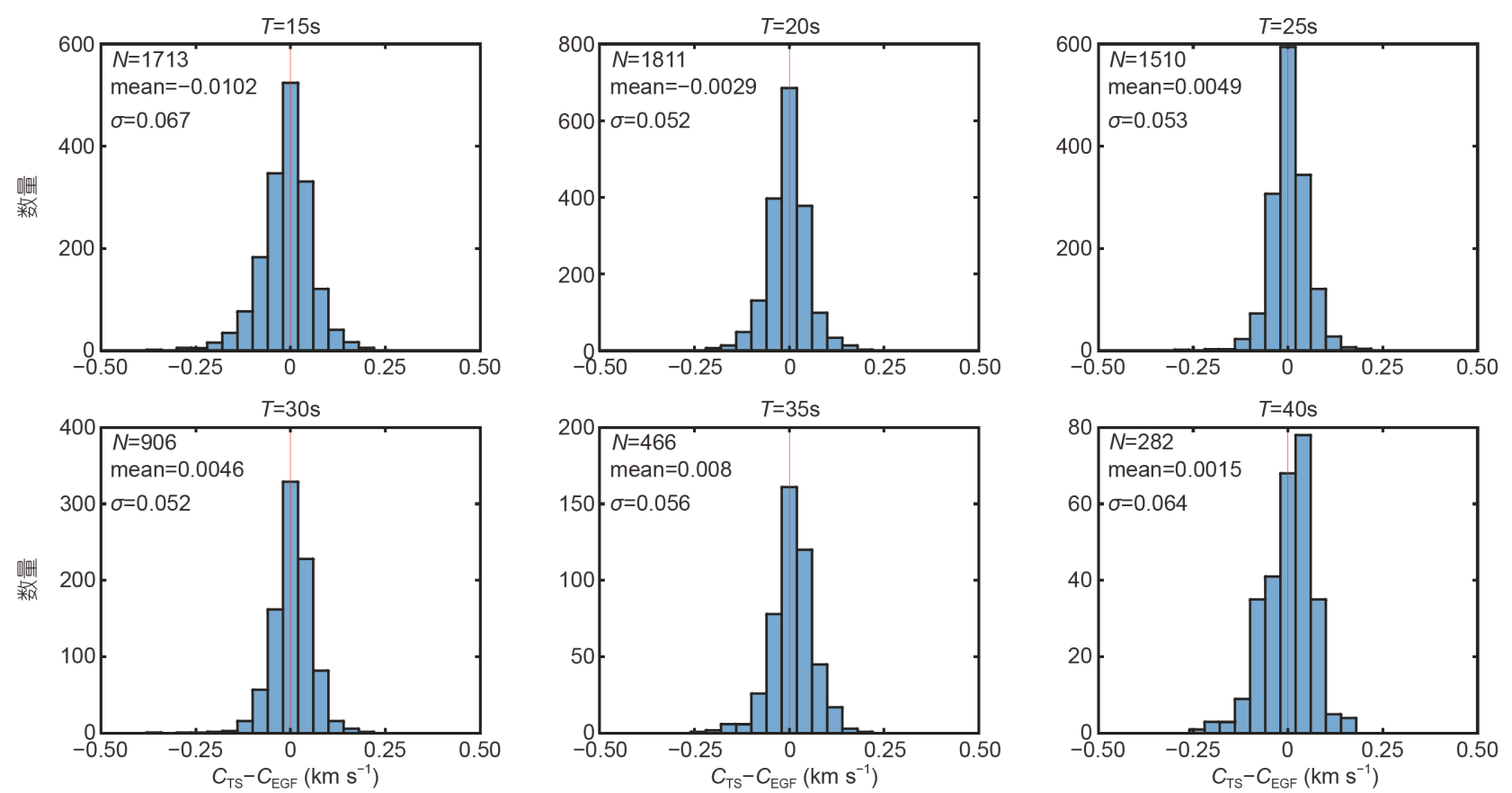

图 4 15 40s通过双台法与背景噪声得到的频散曲线之间偏差的统计直方图

$N$ 表示该周期双台法和背景噪声方法有共同相速度测量的路径数, mean为两种方法测量数据之差的均值(单位: $\mathrm{km} \mathrm{s}^{-1}$ ), $\sigma$ 为标准差(单位: $\mathrm{km} \mathrm{s}^{-1}$ )

反演方法是基于单点反演，相邻点彼此之间没有约束, 而直接反演方法可以对结构的横向变化有较好的平滑 约束; (3) 由于直接反演是基于面波射线追踪计算走时 的, 因此即使某周期的路径覆盖较稀疏, 也可以用于直 接反演，但在两步法中却无法构建该周期的可靠的相 速度或群速度分布图。面波直接反演方法虽然仅反演 三维S波速度结构，但是在反演过程中将P波速度和密 度根据经验公式(Brocher，2005)与S波速度耦合在一 起，因此也考虑了 $\mathrm{P}$ 波速度和密度敏感性对反演结果 的影响, 更详细的反演理论请参考Fang等(2015)的 文章.

本次研究反演了从 $0 \mathrm{~km}$ 到上地幔 $280 \mathrm{~km}$ 深度范围 内的速度结构, 其中地壳部分 $(\leq 50 \mathrm{~km})$ 的初始模型使 用的是Yang等(2020)基于单台频散、瑞利面波振幅比 及接收函数联合反演得到的SWChinaVs_2018模型, 上 地幔部分 $(>50 \mathrm{~km})$ 使用的是 ak135模型 (Kennett等, 1995)作为初始速度模型, 因为本次研究希望获得更为 可靠的上地幔速度结构模型，因此对于地壳部分选用 了一个尽可能准确的三维初始速度模型以减少其对上 地幔部分反演的影响，而上地幔部分采用了简单的一 维层状模型以减少初始模型对反演的影响，使上地幔
部分的反演结果主要受数据控制. 模型水平方向上的 网格划分为 $0.5^{\circ} \times 0.5^{\circ}$, 而在深度上节点的划分为: $0 \sim 70 \mathrm{~km}$ 时每 $5 \mathrm{~km}$ 一层, $70 \sim 115 \mathrm{~km}$ 时每 $7.5 \mathrm{~km}$ 一层; $115 \sim 205 \mathrm{~km}$ 时每 $10 \mathrm{~km}$ 一层, 205 280km时每 $15 \mathrm{~km}$ 一层. 在深度上的节点间距的变化主要是考虑到面波的分辨 率是随深度逐渐减小的.

\section{3 反演结果}

\section{1 检测版测试}

为了测试反演结果的分辨能力, 进行了检测板测 试. 异常体的大小分别为 $70 \mathrm{~km}$ 之上为 $1^{\circ} \times 1^{\circ}, 70 \mathrm{~km}$ 之 下为 $1.5^{\circ} \times 1.5^{\circ}$, 速度扰动为 $\pm 5 \%$ 并分别加入了 $0.5 \%$ 和 $1 \%$ 的走时随机噪声进行测试. 检测板模型的网格划分 与反演中的网格划分完全一致.

图6和图7为检测板测试的横剖面和纵剖面结果, 可以看出在 $70 \mathrm{~km}$ 之上速度异常能够恢复得很好，而到 了深部在研究区域的内部对速度异常也有较好的恢 复. 对比加入 $0.5 \%$ 和 $1 \%$ 随机噪声后的恢复结果, 可以 看出在浅层两者都能恢复得很好，此时基本能恢复 $5 \%$ 的速度异常, 加入 $1 \%$ 噪声的深部检测板恢复结果弱于 

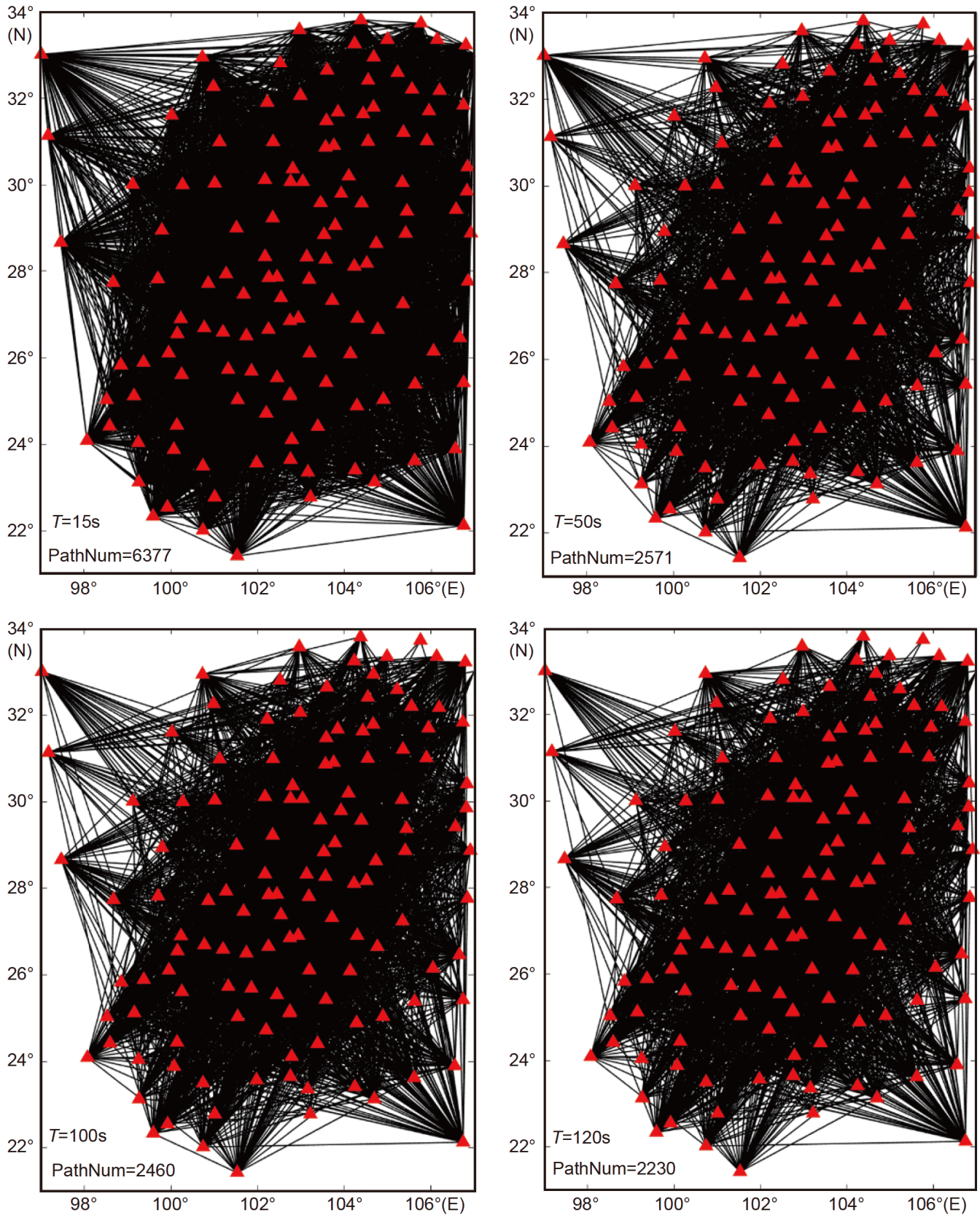

图 $515 、 50 、 100$ 和 $120 \mathrm{~s}$ 周期的路径分布图

红色三角为台站, 黑线为射线路径. 每个图中右下角 $T$ 为周期, PathNum为路径数

加入 $0.5 \%$ 噪声的, 但是检测板模式仍能有较好的恢复, 两者也基本能恢复 $4 \%$ 左右的速度异常.

检测板测试的结果表明我们能够在 $70 \mathrm{~km}$ 之上分 辨出 $1^{\circ} \times 1^{\circ}$ 的异常, 在 $70 \mathrm{~km}$ 之下分辨出 $1.5^{\circ} \times 1.5^{\circ}$ 的异 常，并且能够压制数据中至少 $1 \%$ 的随机噪声. 此外可 以看出受台站分布和路径覆盖的影响(图5), 在研究区
域的西侧恢复效果较差，因此在之后绘制反演结果时 会截取掉研究区域的西侧.

\section{2 三维S波速度结构}

图8是反演得到的从 $10 \sim 235 \mathrm{~km}$ 深度范围的 $\mathrm{S}$ 波速 度模型的水平切片. 在 $10 \mathrm{~km}$ 深度时，四川盆地受浅表 

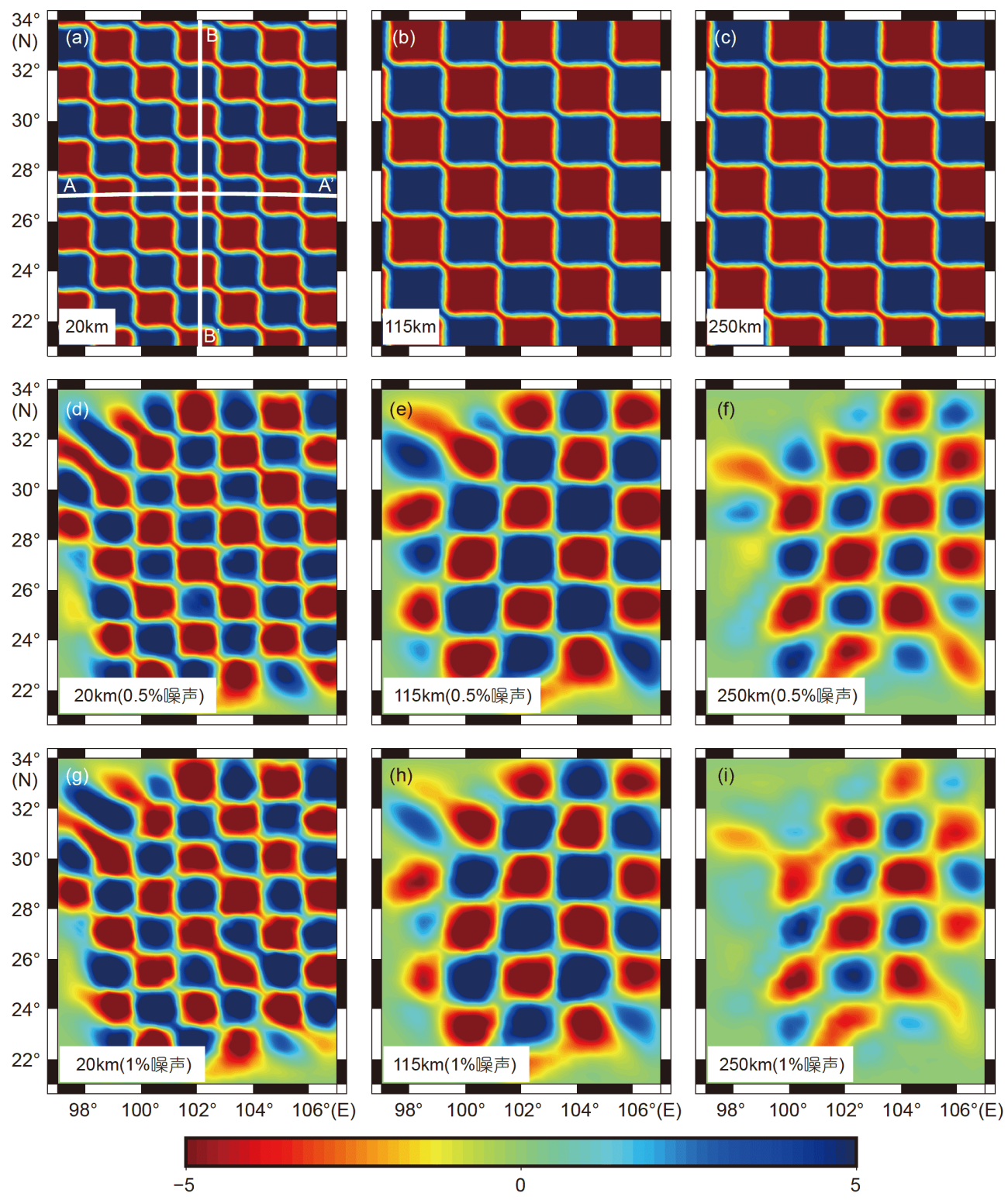

$98^{\circ} 100^{\circ} 102^{\circ} 104^{\circ} 106^{\circ}(\mathrm{E})$

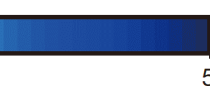

$d V_{s}(\%)$

图 6 检测板测试横剖面结果

检测版输入异常大小为 $5 \%$, (a) (c)为初始模型, (d) (f)为加入 $0.5 \%$ 噪声时恢复的模型, (g) (i) 为加入 $1 \%$ 噪声时恢复的模型

沉积层和龙门山断裂带的影响，在盆地北部呈现非常 明显的低速，位于川滇菱形块体边界的红河和小江断 裂带周边受断层脆性破裂的影响也呈现出低速异常, 而处于块体内部的大部分区域都呈明显高速. $25 \mathrm{~km}$ 深 度时的反演结果基本反映了研究区域中下地壳深度的 $\mathrm{S}$ 波速度结构, 四川盆地从浅表的低速异常转变为明显 的高速异常，华南块体和印支块体呈弱高速异常; 松 潘-甘孜块体呈现明显低速异常，并且该低速异常似乎
沿着丽江-小金河断裂带呈带状向西南延伸; 在扬子克 拉通西缘也出现了一个沿着小江断裂带的低速异常 带, 而绿汁江断裂带北部和安宁河-则木河断裂带附近 却呈明显高速异常，其正好对应峨眉山大火成岩省的 内带和中带区域，此外可以看出此时的高低速异常边 界与断层分布有较好的对应关系. 在 $45 \mathrm{~km}$ 深度时，研 究区域东南部呈高速、西北部呈低速，这主要是受研 究区域的地壳厚度控制的。Wang等(2017)和 $\mathrm{He}$ 等 

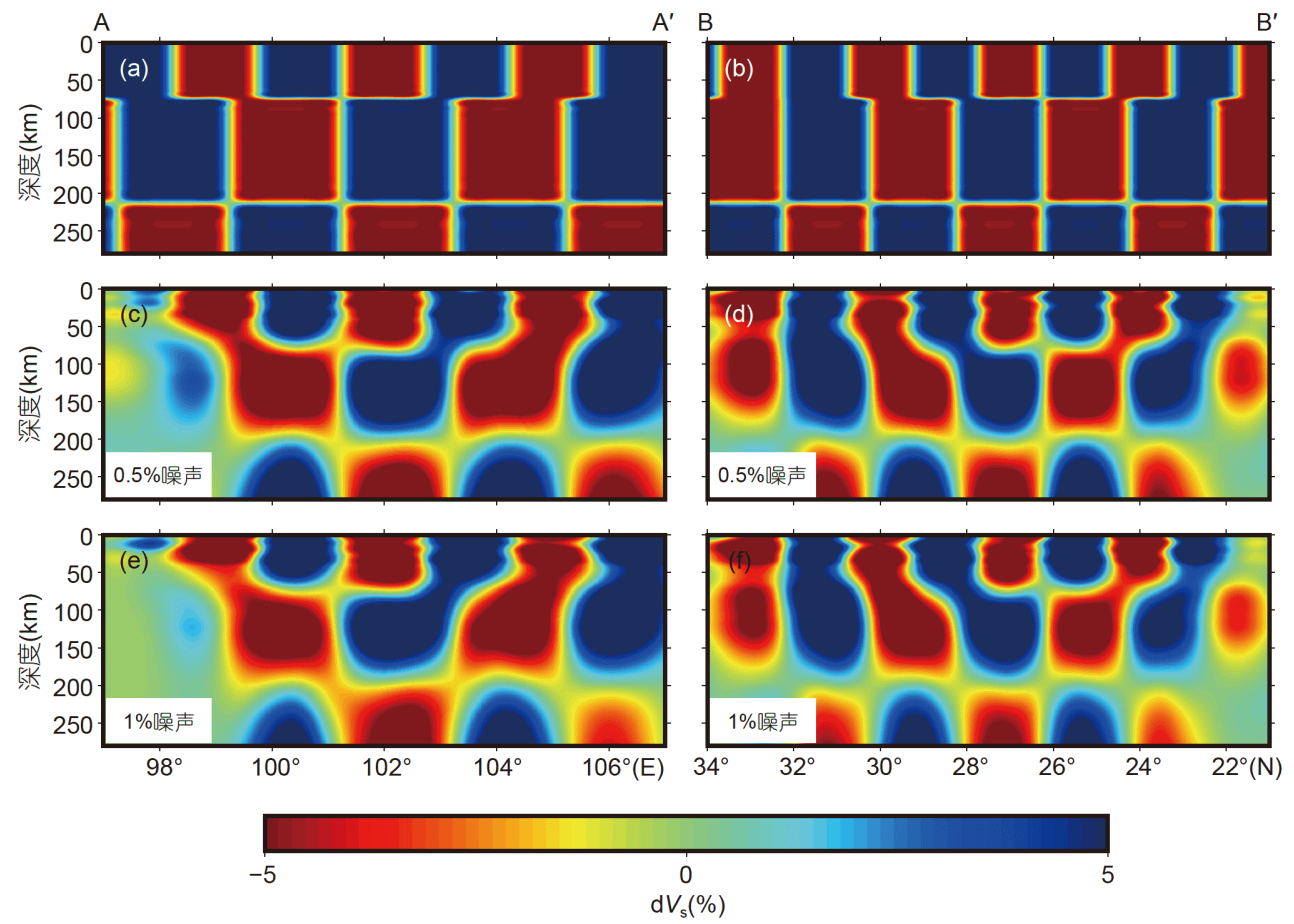

图 7 检测板测试纵剖面结果

纵剖面位置见图6a. (a)和(b)为初始模型, (c)和(d)为加入 $0.5 \%$ 噪声时恢复的模型, (e)和(f)为加入 $1 \%$ 噪声时恢复的模型

(2014)的研究结果表明在研究区域莫霍深度从东南向 西北是逐渐增加的，因此在 $45 \mathrm{~km}$ 深度时研究区域的东 南部已进入了上地幔深度范围，而西北部还处于地壳 内，从而导致了南高北低的速度差异. 在 $70 \sim 115 \mathrm{~km}$ 深 度时，研究区域基本已进入上地幔内，松潘-甘孜块体 的低速异常已基本消失，扬子克拉通呈现明显的高速 异常，而印支块体和华南块体转变为明显的低速异常， 低速异常基本被限制在红河断裂带以南区域. 而在 155 235km深度时，印支块体和华南块体中的低速异 常似乎沿着小江断裂带向北延伸进入了扬子克拉通西 缘，四川盆地中部区域和松潘-甘孜块体仍呈相对 高速.

图9展示了图 $8 \mathrm{~b} 、 8 \mathrm{f}$ 和 $8 \mathrm{~h}$ 中所示的八个剖面. 从 $\mathrm{CC}^{\prime}$ 和 $\mathrm{DD}^{\prime}$ 剖面中的地壳部分可以很明显地看到在中 下地壳部分，大概20 45km深度范围内存在一个低速 带，其中 $\mathrm{CC}^{\prime}$ 中的低速带向南延伸到 $26^{\circ}$ 左右, $\mathrm{DD}^{\prime}$ 中的 低速带向南跨过红河断裂带延伸到 $22^{\circ}$ 左右. 在横跨这 两个低速带的 $\mathrm{AA}^{\prime}$ 剖面和横跨红河断裂带的 $\mathrm{BB}^{\prime}$ 剖面 中, 可以看到这两个低速带之间似乎并未连通: 在 $\mathrm{AA}^{\prime}$ 剖面中，在 $102 \circ$ 左右有一个柱状高速体将低速体隔开，
其对应于峨眉山大火成岩省的范围内，可能是地幔柱 物质在地壳中的残留，在 $\mathrm{BB}^{\prime} 、 \mathrm{GG}^{\prime}$ 和 $\mathrm{HH}^{\prime}$ 剖面的地壳 部分都可以看到这样一个非常明显的柱状高速体; 在 $\mathrm{BB}^{\prime}$ 剖面的地壳部分中可以看到在红河断裂带下方有 一个向南倾斜的低速体，不过其较为狭窄细长且速度 略高于两条低速带. 在EE'剖面的地壳部分中也可以明 显看到在红河断裂带下方有一个向西倾斜的低速体， 并且在地幔部分的剖面中可以看到在 $60 \mathrm{~km}$ 深度以上， 以红河断裂带为界东侧和西侧分别呈高速和低速，这 表明红河断裂带是一个向西南倾斜的切穿地壳的断裂 带. 在 $\mathrm{FF}^{\prime}$ 剖面地幔部分的南侧 $24^{\circ} \sim 26^{\circ}$ 可以看到一个 十分明显的柱状低速异常，其正好对应地表腾冲火山 的所在地.

\section{4 讨论}

\section{1 小江断裂带区域的壳内低速带}

小江断裂带在地壳浅层(图8a)呈现出低速异常, 主要沿着断裂带分布，小江断裂带以东区域未出现低 速异常，此时低速异常应该主要是由于断层的脆性破 


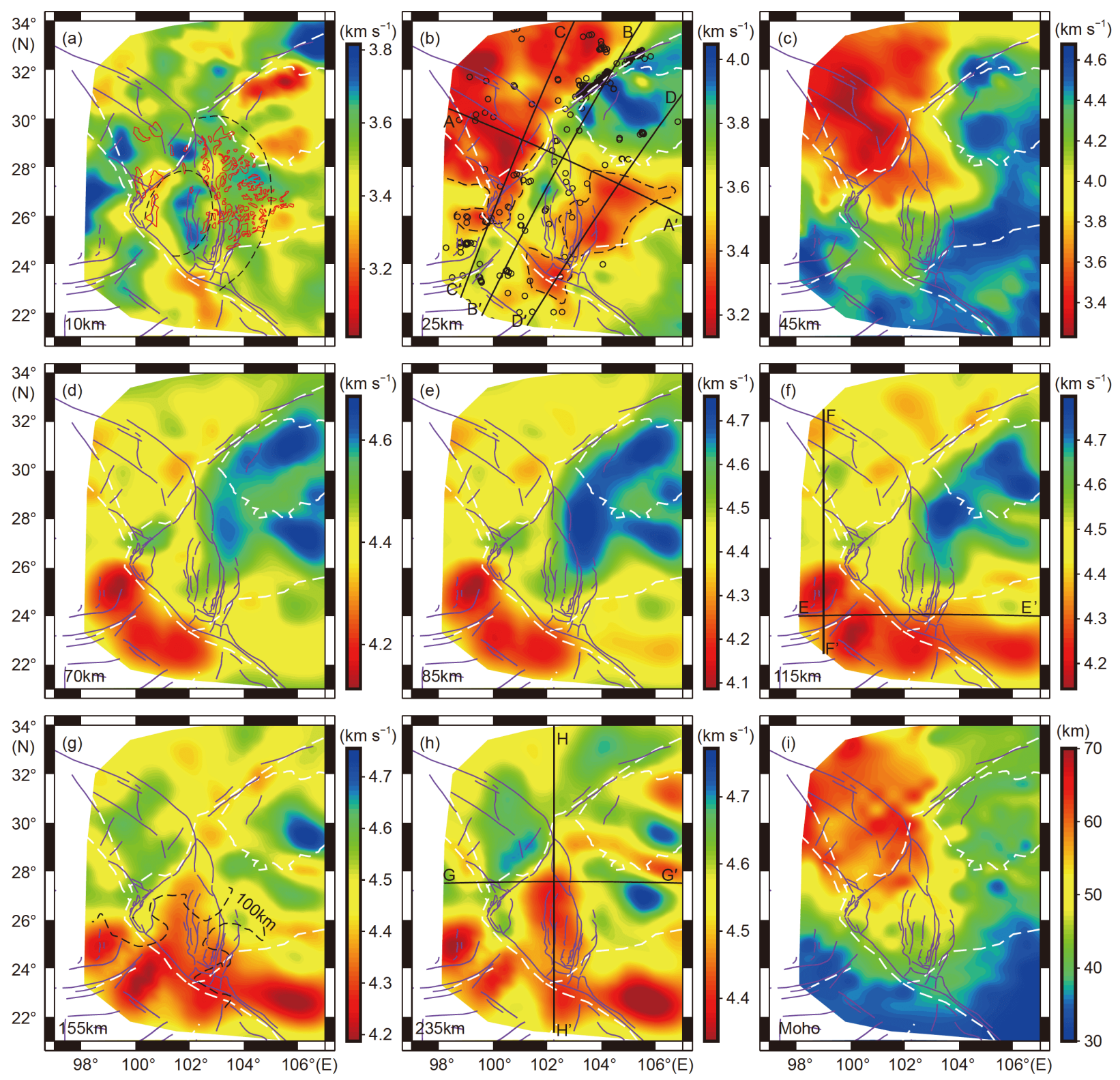

图 8 研究区域的S波速度水平切片 $((\mathbf{a}) \sim(\mathbf{h}))$ 和莫霍深度(i)

图中紫色实线为断层, 白色虚线为块体边界, 同图1. (a)中黑色虚线为峨眉山大火成岩省的内带和中带 $(\mathrm{Xu}$ 等, 2004), 红色线条圈闭为地表玄武 岩分布; (b)中黑色虚线为两个低速带的边界, 黑色圆圈代表1970 2012年之间深度范围在20 30km的震级大于4级的地震; $(\mathrm{g})$ 中黑色虚线为岩 石圈厚度为100km的等值线, 修改自Yang等(2017); (i)为莫霍面深度, 数据来源于Wang等(2017)和He等(2014)

裂和剪切生热引起的. 结合地表GPS速度场的观测结 果(Zhang等，2004)，我们认为这表明了青藏高原东南 缘在上地壳的运动变形主要是受到大规模走滑断层的 控制, 上地壳的运动机制更符合刚性块体挤出模型 (Tapponnier等, 1982, 2001), 这也与一些前人的结论相 符(Fu等, 2017; Yao, 2012; Qiao等, 2018).
在中下地壳深度上 $(25 \mathrm{~km})$ 可以看到两个明显的带 状低速体(图 $8 \mathrm{~b}$ 中虚线部分): 西侧的低速体主要以龙 门山-丽江-小金河-程海断裂带为界, 广泛分布在松潘甘孜块体和川滇菱形块体西北部, 并可能向西南延伸 到东喜马拉雅构造结附近(Bai等，2010); 东侧的壳内 低速体主要分布在小江断裂带及其东侧的云贵高原下 

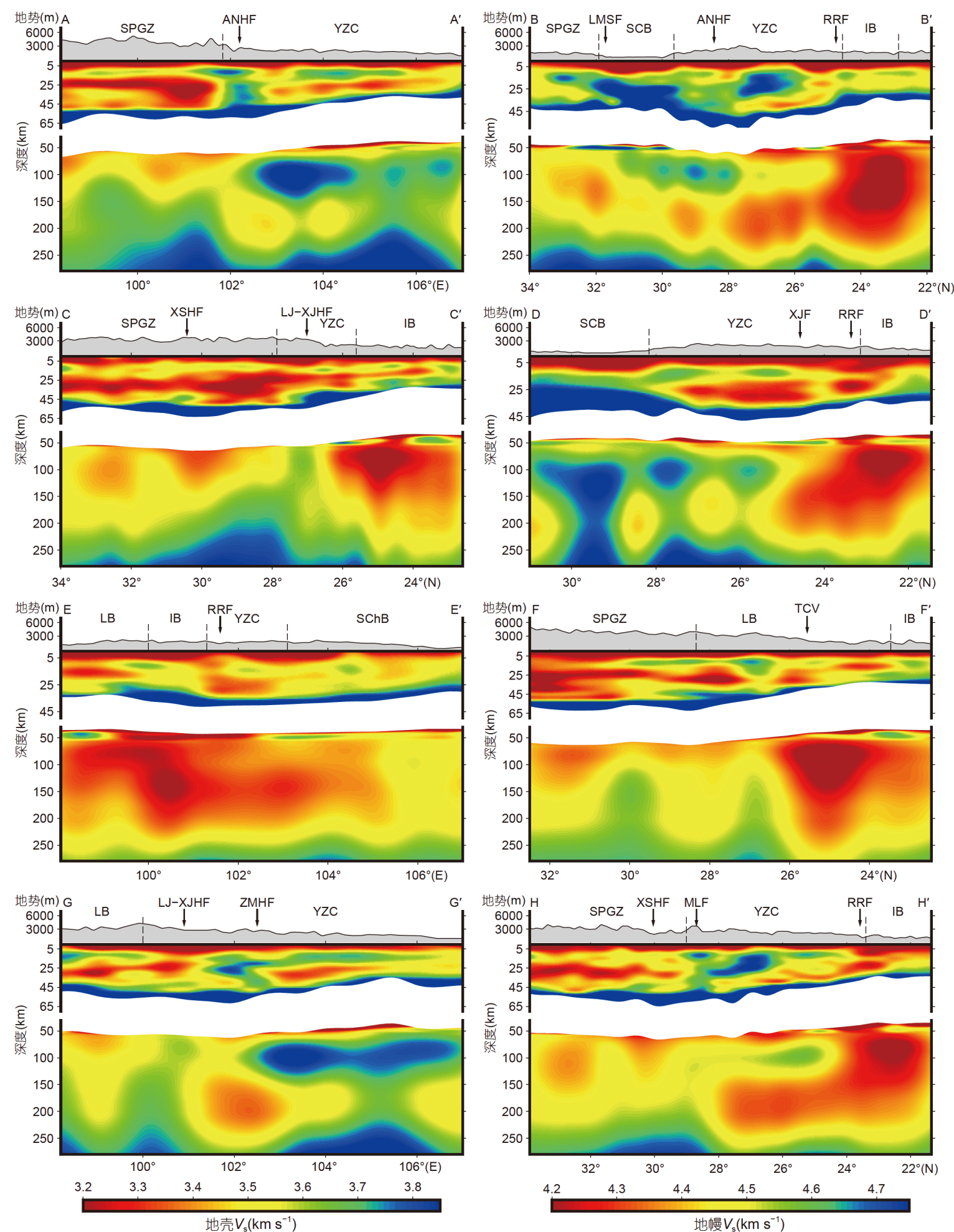

图 9 研究区域的S波速度垂直剖面

剖面位置见图 $8 \mathrm{~b} 、 8 \mathrm{f}$ 和 $8 \mathrm{~h}$, 其中每个剖面上图展示的是地壳部分的速度结构, 下图展示的是地幔部分的速度结构. 地壳和地幔是基于Moho深 度进行划分, Moho深度来源于图8i. 图中白色空白主要是由于地壳和地幔部分深度和横向比例不一致导致的图像拉伸引起的. 左侧色标适用 于地壳部分的速度结构, 右侧的色标适用于地幔部分的速度结构 
方, 向南延伸跨过了红河断裂带, 并很可能延伸到越南 奠边府断裂带的西侧区域(Qiao等, 2018). 我们观测到 的小江断裂带及其东侧区域的低速体位置和形态与前 人的研究结果也较为一致(Bao等, 2015; Chen等, 2016; Fu等, 2017; Qiao等, 2018). 但是受研究区域大小的限 制，前人的结果并未很好地展示这两个壳内低速体与 松潘-甘孜块体东缘以及彼此之间的连通性，但在我们 的结果中, 由于将研究区域向北拓展了很多, 可以清楚 地看到西侧的壳内低速体广泛分布在研究区域的西北 部，因此认为该低速体极有可能是青藏高原物质向东 南缘挤出形成的，这也与前人的结论相符；不过对于 东侧的低速体，可以看到在其北侧的安宁河-则木河断 裂带附近是呈高速异常, 将其和西北侧的川滇菱形块 体中的低速体所隔开. 从图 $8 \mathrm{~b}$ 可以看出在 $20 \sim 30 \mathrm{~km}$ 深 度范围内在安宁河-则木河断裂带，丽江-小金河断裂 带附近以及小江断裂带西侧均分布有较多地震，而小 江断裂带东侧的大范围低速异常和安宁河-则木河断 裂带西南侧的高速体中却几乎没有地震，而关于地震 分布的研究表明地震更易发生在高低速体的边界

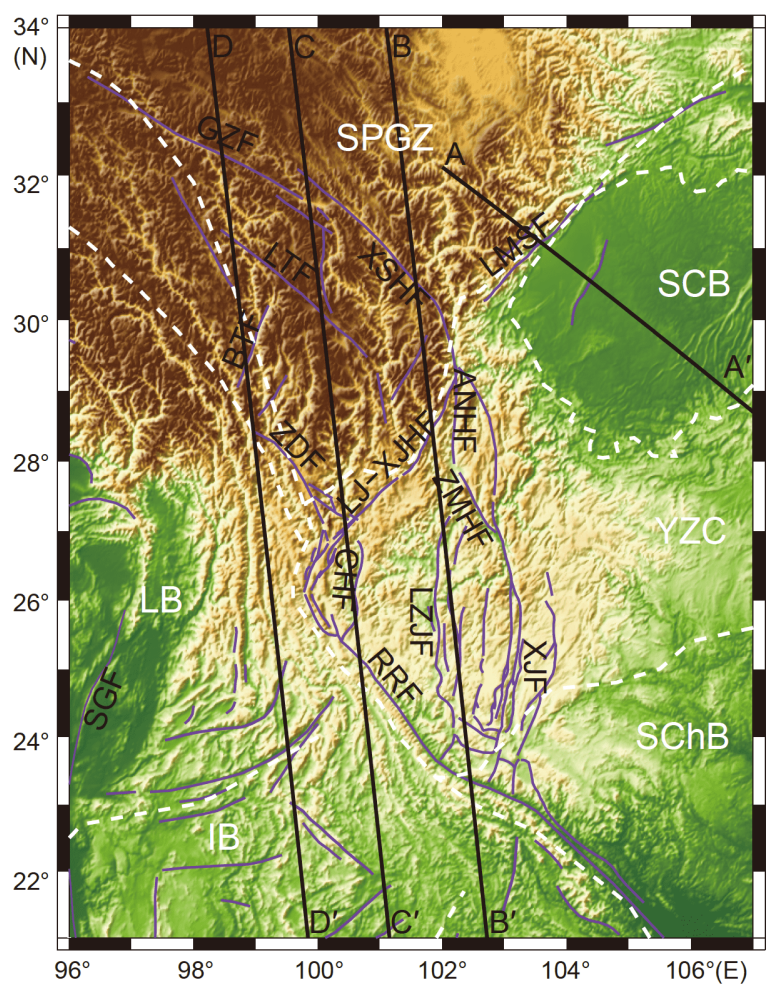

(Mooney等, 2012; Lei等, 2014), 因为这些区域更容易 累积应变. 另外从图10的AA'剖面可以看出松潘-甘孜 中的低速体受坚硬的四川盆地阻挡，在龙门山断裂带 附近地形变化十分陡峭，而在 $\mathrm{BB}^{\prime}$ 和 $\mathrm{CC}^{\prime}$ 剖面中可以看 出在丽江-小金河断裂带附近的地形变化也是较为陡 峭的, 而在更西边的 $\mathrm{DD}^{\prime}$ 剖面中地形变化就较为平缓. Clark和Royden(2000)以及Royden等(2008)的研究认为 如果中下地壳中软弱的低速带物质被坚硬的高速体所 阻挡, 反映到地表则会出现较为陡峭的地形变化, 反之 则会是较为平缓的地形变化. 因此我们认为从 $\mathrm{S}$ 波速 度、地震分布和地表地形起伏这三个方面的结果都直 接或间接地证明了东侧沿着小江断裂带的低速带与西 侧沿着丽江-小金河断裂带的低速带是被一个相对坚 硬的高速体所隔开的.

从图 $8 \mathrm{a} \sim 8 \mathrm{~b}$ 可以看出南侧的红河断裂带在壳内整 体也呈相对低速，不过我们认为红河断裂带下方的低 速主要是由于其是一个切穿整个地壳的深大断裂导致 的，从图9的BB'剖面也可以看出位于这两个低速带之 间的红河断裂带下方的低速带较为狭长, 且速度略高

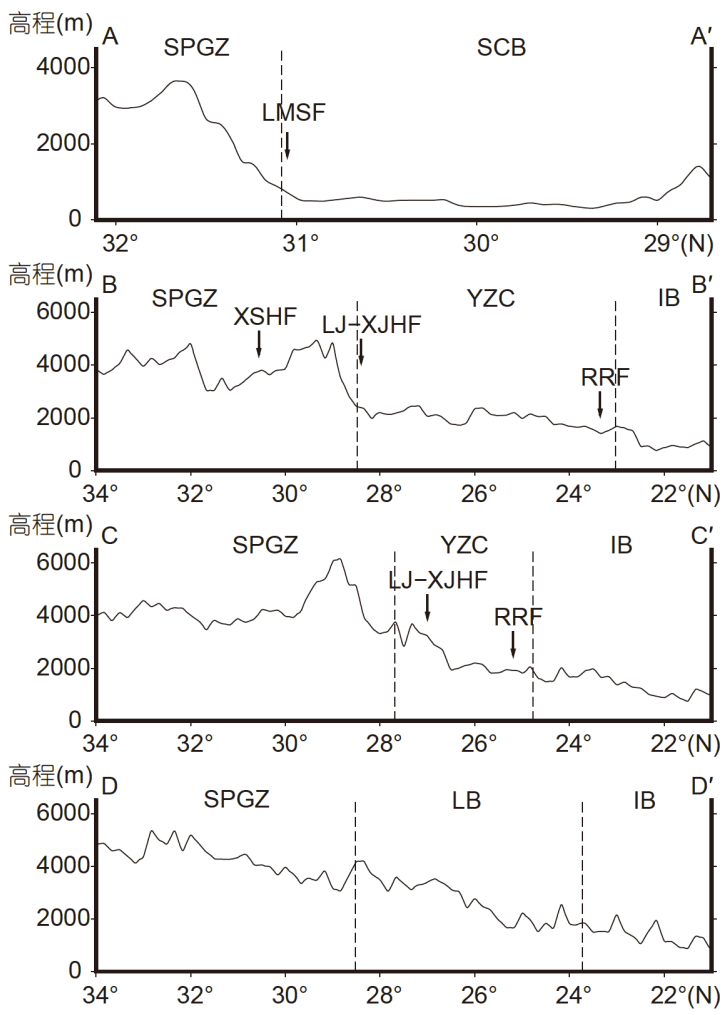

图 10 研究区域的地形起伏

剖面位置见左图中黑线, 紫线和白色虚线显示断裂带和块体边界位置, 符号缩写同图1 
(a)

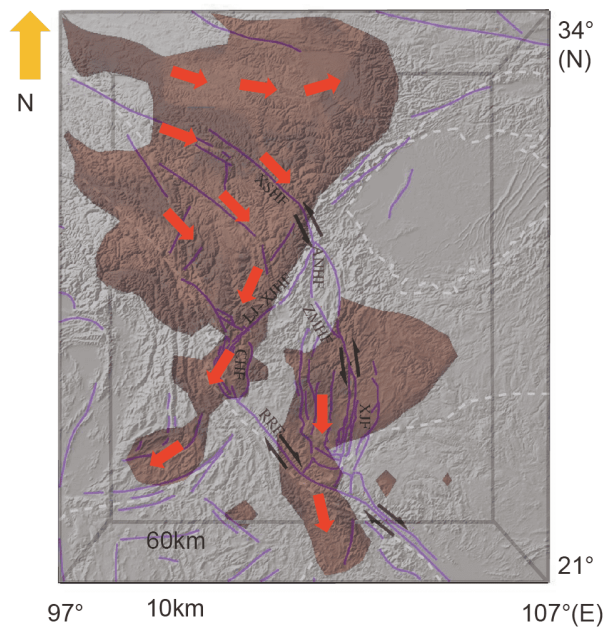

(b)

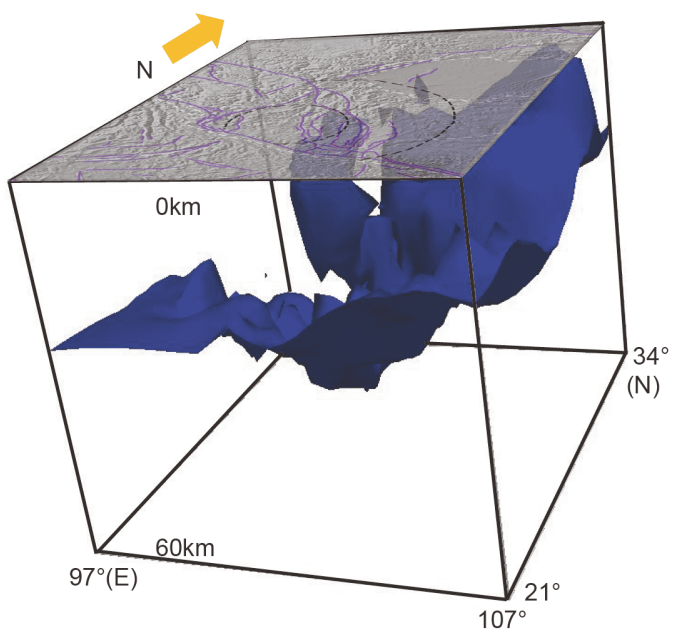

图 11 两条壳内低速带(a)和峨眉山大火成岩省(b)的三维可视图

低速带(a)对应速度为 $V_{\mathrm{S}}=3.40 \mathrm{~km} \mathrm{~s}^{-1}$, 高速体(b)对应速度 $V_{\mathrm{S}}=3.65 \mathrm{~km} \mathrm{~s}^{-1}$. 紫线和白色虚线为断裂带和块体边界, 符号缩写同图1. (a)中的橙色箭 头是可能的低速带物质运移方向, 黑色半箭头为断层滑动方向, (b) 中的黑色虚线为峨眉山大火成岩省的内带和中带

于丽江-小金河和小江断裂带下方的低速带. 在图11a 中的三维图可以更加清楚的看到两条低速带在南侧并 未通过红河断裂带未互相连通，而在北侧也被安宁河则木河断裂带下方的高速体所阻隔. 综上我们认为小 江断裂带附近的低速带很可能并不是由于青藏高原的 物质挤出形成的.

由图 $8 \mathrm{~g}$ 和 $8 \mathrm{~h}$ 可以看出, 小江断裂带及其东侧区域 下方的上地幔顶部部分的速度结构在 $155 \mathrm{~km}$ 之后也是 呈低速异常, 但是在 70 155km(图8d 8f)之间小江断裂 带及其东侧区域下方的速度结构都呈明显的高速异 常, 而在 $\mathrm{DD}^{\prime}$ 和 $\mathrm{GG}^{\prime}$ 剖面中也可以很清楚的看到小江断 裂带下方的地壳低速体和上地幔顶部的低速体中间夹 了一个较厚的高速体, 表明地壳中的低速与上地幔中 的低速之间并未连通. 对小江断裂带附近温泉和矿物 的氦同位素分析结果也表明该区域的壳幔连通程度较 低(王云等, 2014; 王健等, 2018), 这些资料也都从侧面 支持了我们的反演结果，因此认为小江断裂带及其东 侧区域下方地壳内的低速带也不是由于上地幔热源导 致壳内发生熔融引起的.

不过对于该区域的泊松比的研究表明小江断裂带 及其东边的大片区域呈相对较低的泊松比值(Wang等, 2017), 我们推测其地壳组分可能是以长英质为主, 更 易发生熔融，而该低速带主要位于小江断裂带及云贵 高原的下方, Moho面深度(图8i)也表明该处地壳厚度
(大约 40 $50 \mathrm{~km}$ ) 相对平均大陆地壳厚度也有一定程度 的增厚，因而高原隆升导致的地壳增厚可能使该区域 的地壳温度也相对较高; 此外该区域地表热流的研究 表明小江断裂带是个地表热流值相对偏高的区域(王 云等, 2014; Shi和Wang, 2017), 因此我们认为该低速带 很有可能是长英质地壳在相对较高的地壳温度下发生 塑性变形甚至部分熔融形成的. 大地电磁的结果( $\mathrm{Li}$ 等, 2019)也表明小江断裂带下方的地壳是呈低阻的, 可能 有流体或熔体存在, 并且小江断裂带北段的平均滑移 量为 $\sim 10 \mathrm{~mm} \mathrm{a}^{-1}$, 南端的平均滑移量为 $\sim 3.5 \mathrm{~mm} \mathrm{a}^{-1}$ (徐锡伟等, 2003), 而如此高的断层滑移量导致的剪切 生热很可能会进一步的加剧地壳物质塑性变形或部分 熔融. 综上, 我们认为主要是长英质地壳的塑性变形甚 至部分熔融导致了小江断裂带下方中下地壳中大规模 低速带的形成, 流体或熔体的存在以及断层剪切生热 加剧了这一效应，进一步扩大了低速带的范围. 不过, 小江断裂带区域的低速体并没有松潘-甘孜块体中的 低速体那么低速, 因此其部分熔融程度可能相对较少, 导致该区域的泊松比并未显著升高. 此外对于该区域 的径向各向异性研究表明小江断裂带下方的地壳中呈 现很强的正径向各向异性，SV波速度远远低于SH波 的速度(Huang等, 2010; 陈浩朋等, 2018), 而本次研究 从瑞利面波里面获得的是SV波速度, 因此我们认为径 向各向异性也一定程度上增强了对小江断裂带下方低 
速带的观测. 不过值得注意的是小江断裂带下方的低 速带很可能一直在向南延伸并跨过了红河断裂, 而成 像结果表明红河断裂以南区域的上地幔呈大范围低速 (图8d 8h), 因此我们认为该区域壳内低速体的成因更 有可能是与上地幔热物质上涌密切相关.

结合前人的研究结果(Bao等, 2015; Lei和Zhao, 2016; Fu等, 2017; Qiao等, 2018), 我们认为分布在松 潘-甘孜块体和川滇菱形块体西北部中下地壳中的低 速带主要来源于青藏高原低黏性物质的东向挤出，在 受到坚硬的四川盆地和峨眉山大火成岩省的阻隔后转 向西南方向运移；小江断裂带及其东侧区域下方的低 速带则主要来源于中下地壳本身的增厚熔融, 但是受 区域应力场和附近的小江断裂带走滑的影响，壳内低 速物质可能也在向南迁移, 并跨过红河断裂带(图11a), 而红河断裂带以南区域的低速带更可能是由于上地幔 热源引起的. 因此我们认为该区域中下地壳物质很有 可能存在塑性流动，更符合中下地壳流模型(Royden 等，1997，2008; Clark和Royden，2000；Beaumont等, 2001).

\section{2 峨眉山大火成岩省高速异常}

峨眉山大火成岩省位于研究区域的中心地带，大 量研究表明其大概形成在 250Ma左右，并且可能与 地幔柱的活动以及瓜德鲁普末期的生物大灭绝有关 (徐义刚和钟孙霖, 2001; Ali等, 2005; Zhou等, 2002). 图8a中的黑色虚线代表峨眉山大火成岩省的内带和 中带, 可以看出在地壳中其呈现出明显的高速(图8a和 $8 b)$, 并且该高速区域也广泛分布有铅锌矿, 研究表明 其与峨眉山大火成岩省岩浆活动有关 (黄智龙等, 2001; 孔志岗等, 2018; 王健等, 2018; 江小均等, 2018), 这也从侧面印证了观测到的高速体的可靠性以及其 与峨眉山大火成岩省的关系. 从图9的 $\mathrm{AA}^{\prime} 、 \mathrm{BB}^{\prime} 、 \mathrm{GG}^{\prime}$ 和 $\mathrm{HH}^{\prime}$ 剖面的地壳部分中也可以十分清楚的看见在 $\left(102^{\circ} \mathrm{E}, 28^{\circ} \mathrm{N}\right)$ 附近有一个略向南倾斜的柱状高速体, 大致从 $10 \mathrm{~km}$ 处向下一直延伸到莫霍面, 其正好对应地 表峨眉山大火成岩省内带和中带的西北部，从图 $11 \mathrm{~b}$ 可以更清楚的看到该高速柱状体的三维分布. 结合前 人的研究我们认为该柱状高速体很可能是峨眉山大 火成岩省形成时侵入地壳中的基性-超基性物质导致 的(Xu和He, 2007; Chen等, 2010).

不过值得注意的是我们所观测到的柱状高速体主
要位于峨眉山大火成岩省的内带区域，而中带区域除 了在上地壳 $\left(<25 \mathrm{~km}\right.$ ，图 $8 \mathrm{a} 、 8 \mathrm{~b}$ 及图9中AA'、 $\mathrm{BB}^{\prime} 、 \mathrm{GG}$ '和HH'剖面)呈相对高速外, 在中下地壳均呈相对低速. 其他研究者的 $\mathrm{S}$ 波速度成像结果中也观测到峨眉山大 火成岩省内带和中带的速度差异(Bao等，2015; 郑晨 等, 2016; Yang等, 2020), 并且径向各向异性的研究表 明柱状高速体所在的内带区域呈较强的负径向各向异 性(Huang等, 2010), 即物质的晶格排列以垂直向为主, 表明内带区域的地壳中的物质很可能经历过垂向的运 移. 除此之外, 重力异常观测以及 $V_{\mathrm{P}} / V_{\mathrm{S}}$ 波速比结果均 显示了内带和中带的差异性: 内带呈很高的正剩余重 力异常(Deng等, 2014, 2016), 从内带向中带剩余重力 异常在逐渐降低; $V_{\mathrm{P}} / V_{\mathrm{S}}$ 波速比也是从内带向中带在逐 渐降低(Wu和Zhang, 2012; Sun等, 2014). 这种地球物 理性质的差异表明形成峨眉山大火成岩省的地幔柱的 柱头是很可能位于内带的下方，这也与前人的推论一 致(Xu等, 2004; Chen等, 2015).

\section{3 印支块体和华南块体上地幔动力学过程}

在图 8 中可以看到另一个很明显的特征就是在 $70 \mathrm{~km}$ 之后印支块体和华南块体中出现的大范围的低 速异常, 前人也观察到了类似的现象 ( $\mathrm{Li}$ 等, 2008; Huang等, 2013; Bao等, 2015; Lei和Zhao, 2016; Fu等, 2017). 从图 $8 \mathrm{~d} \sim 8 \mathrm{~h}$ 可以看出从 $70 \mathrm{~km}$ 开始印支块体中出 现了大规模的低速异常, 随着深度增加低速体逐渐向 东以及向北延伸进入了华南块体和扬子克拉通中. 从 $\mathrm{EE}$ '剖面中可以看出在大约 $60 \mathrm{~km}$ 之，低速体被红河 断裂带限制在印支块体中, 而在 $60 \mathrm{~km}$ 之下低速体向东 跨过红河断裂带延伸到了华南块体下，另外从 $\mathrm{HH}^{\prime}$ 剖 面中可以看到在大约在 $150 \mathrm{~km}$ 之, 低速异常沿着小 江断裂带向北跨过红河断裂带延伸到了扬子克拉通 下, 不过只向北延伸到 $28^{\circ}$ 左右, 所以我们认为该低速 异常不可能来自于北部的青藏高原.

结合前人的研究结果，印支块体和华南块体上地 幔顶部大范围低速异常的成因可能有两个: 第一个原 因是由于印支块体和华南块体下方的岩石圈发生了大 范围拆沉，使得软流圈上涌. Chung等(1997)认为在约 $30 \mathrm{Ma}$ 左右在该区域由于岩石圈增厚拆沉引起了板内 伸展活动，导致了该区域高钾镁铁质岩浆的喷出; $\mathrm{Hu}$ 等(2012)和Yang等(2017)的S波接收函数结果也明确显 示了该区域岩石圈较薄，大部分地区不足 $100 \mathrm{~km}$ (图 $8 \mathrm{~g}$ 
中虚线), 从图 $8 \mathrm{~g}$ 可以看出在 $102^{\circ} \mathrm{E}$ 附近, 岩石圈减薄的 区域 $(<100 \mathrm{~km})$ 向北延伸到了 $27^{\circ} \mathrm{N}$ 附近, 而从 $\mathrm{GG}^{\prime}$ 和 $\mathrm{HH}^{\prime}$ 剖面可以看出扬子克拉通中的低速体基本只位于 $28^{\circ}$ $\mathrm{N}$ 以南和 $101^{\circ} \sim 103^{\circ} \mathrm{E}$ ，与扬子克拉通中岩石圈减薄的 区域有较好的对应关系.

第二个原因可能是由于印度板块的东向俯冲及后 撤. 大量体波成像的结果(Li等, 2008; Lei和Zhao, 2016) 表明在 $26^{\circ} \mathrm{N}$ 以南的区域，印度板块在向东俯冲并下插 到了缅甸弧下方的地幔转换带，而随着印度板块的俯 冲脱水作用, 使得大量热的和湿的物质从地幔转换带 上涌，最终可能导致了该区域的大范围低速异常以及 腾冲火山的形成, 不过其影响还有待更进一步的研究.

\section{5 总结}

本次研究使用了布设在青藏高原东南缘的 132 个 固定地震台站在 10 年间记录到的中长周期的地震瑞利 面波数据(15 150s), 并融合了从背景噪声中提取到的 中短周期的瑞利面波数据(5 40s), 通过面波直接反演 方法得到了该区域地壳上地幔高分辨率的 $\mathrm{S}$ 波速度结 构模型. 我们主要得到了以下几点结论.

（1）小江断裂带及其东侧区域下方的中下地壳低 速带在北部被峨眉山大火成岩省下方的高速体所阻 隔, 并未与西北方川滇菱形块体和松潘-甘孜块体中的 大片低速异常连通，南部也未通过红河断裂带与沿着 丽江-小金河断裂带向西南延伸的低速带之间连通，因 此这个低速体很可能不是由青藏高原地壳物质挤出形 成的. 综合其他地球物理资料分析认为小江断裂带下 方的低速体主要成因可能是由于其地壳组分以长英质 为主, 地壳增厚导致其发生了部分熔融, 断层剪切生热 以及流体或熔体的存在加剧了熔融，进一步扩大了低 速带的范围. 此外，显著的正径向各向异性也一定程 度上增强了对小江断裂带下方低速带的观测. 小江断 裂带的壳内低速异常体向南跨过红河断裂带延伸到越 南北部，红河断裂带以南壳内低速异常的形成可能主 要是由于上地幔热源引起的.

(2) 在峨眉山大火成岩省内带的下方观测到一个 柱状高速体，其可能是峨眉山大火成岩省形成时侵入 地壳中的基性-超基性物质导致的, 不过高速异常主要 位于内带区域. 综合其他各种地球物理观测资料, 认为 这是由于形成峨眉山大火成岩省的地幔柱的柱头是位
于内带的下方导致的.

（3）在印支块体和华南块体地幔中大范围的低速 异常可能是由于岩石圈发生了拆沉，以及印度板块在 缅甸弧下方深俯冲形成“大地幔楔”中的热物质上涌密 切相关.

(4) 基于研究结果, 我们认为青藏高原东南缘可能 正同时经历三种不同模式的构造运动: 在上地壳, 运动 受大型走滑断裂带控制, 主要呈刚体挤出模式; 在中下 地壳, 地壳物质黏性显著降低, 部分区域在区域应力场 和走滑断裂带的影响下主要呈塑性流动; 到了上地幔 顶部，南部印支块体和华南块体岩石圈发生拆沉减薄 和热物质上涌，随后被印度板块在缅甸弧下方深俯冲 引起的大量上涌软流圈物质所填充.

致谢感谢国家测震台网数据备份中心为本研究提供了 固定台站的连续波形数据(doi:10.11998/SeisDmc/SN, http://www.seisdmc.ac.cn). 感谢两位审稿人、编委及执行 主编对本文提出的修改意见和建议. 本研究反演获得的 三维速度模型文件请见网络版附件文档SWChinaVs_CUM_2020.txt(http://earthcn.scichina.com), 其中P波速度和 密度是根据经验公式(Brocher, 2005)由 $\mathrm{S}$ 波速度转换得到。

\section{参考文献}

陈浩朋, 李志伟, 储日升, 谢军, 崇加军, 叶庆东. 2018. 云南地区地壳 上地幔三维 $\mathrm{S}$ 波速度与径向各向异性结构研究. 地球物理学报, 61: 3219-3236

黄智龙, 陈进, 刘丛强, 韩润生, 李文博, 赵德顺, 高德荣, 冯志宏. 2001. 峨眉山玄武岩与铅锌矿床成矿关系初探——以云南会泽 铅锌矿床为例. 矿物学报, 21: 681-688

江小均, 王忠强, 李超, 郭忠林, 柴建华, 邱文龙, 王加昇. 2018. 滇东 北会泽超大型铅锌矿 Re-Os同位素特征及喜山期成矿作用动力 学背景探讨. 岩矿测试, 37: 448-461

孔志岗, 吴越, 张锋, 张长青, 孟旭阳. 2018. 川滇黔地区典型铅锌矿床 成矿物质来源分析: 来自 $\mathrm{S}-\mathrm{Pb}$ 同位素证据. 地学前缘, 25: 125-137 刘建华, 刘福田, 何建坤, 陈辉, 游庆瑜. 2000. 攀西古裂谷的地震成 像研究——壳幔构造特征及其演化推断. 中国科学 $\mathrm{D}$ 辑: 地球科 学, 30(增刊): 9-15

孙洁, 晋光文, 白登海, 王立风. 2003. 青藏高原东缘地壳、上地幔电 性结构探测及其构造意义. 中国科学 D辑: 地球科学, 33: 173-180 王健, 张均, 仲文斌, 杨清, 李发科, 朱政坤. 2018. 川滇黔地区天宝山, 会泽铅锌矿床成矿流体来源初探: 来自流体包裹体及氦氩同位 素的证据. 地球科学, 43: 2076-2099

王琼, 高原, 石玉涛. 2015. 青藏高原东南缘基于背景噪声的Rayleigh 
面波方位各向异性研究. 地球物理学报, 58: 4068-4078

王云, 赵慈平, 刘峰, 陈坤华, 再华. 2014. 小江断裂带及邻近地区温 泉地球化学特征与地震活动关系研究. 地震研究, 37: 228-243

徐涛, 张忠杰, 刘宝峰, 陈望, 张明辉, 田小波, 徐义刚, 滕吉文. 2015. 峨眉山大火成岩省地壳速度结构与古地幔柱活动遗迹: 来自丽 江-清镇宽角地震资料的约束. 中国科学: 地球科学, 45: 561-576 徐锡伟, 闻学泽, 郑荣章, 马文涛, 宋方敏, 于贵华. 2003. 川滇地区活 动块体最新构造变动样式及其动力来源. 中国科学 $\mathrm{D}$ 辑: 地球科 学, 33(增刊): 151-162

徐义刚, 钟孙霖. 2001. 峨眉山大火成岩省: 地幔柱活动的证据及其 熔融条件. 地球化学, 30: 1-9

姚华建, 徐果明, 肖翔, 朱良保. 2004. 基于图像分析的双台面波相速 度频散曲线快速提取方法. 地震地磁观测与研究, 25: 1-8

张耀阳, 陈凌, 艾印双, 姜明明, 许卫卫, 申中寅. 2018. 利用S波接收 函数研究华南块体的岩石圈结构. 地球物理学报, 61: 138-149

郑晨, 丁志峰, 宋晓东. 2016. 利用面波频散与接收函数联合反演青 藏高原东南缘地壳上地幔速度结构. 地球物理学报，59：32233236

郑秀芬, 欧阳謎, 张东宁, 姚志祥, 梁建宏, 郑洁. 2009. “国家数字测 震台网数据备份中心”技术系统建设及其对汶川大地震研究的 数据支撑. 地球物理学报, 52: 1412-1417

Ali J R, Thompson G M, Zhou M F, Song X. 2005. Emeishan large igneous province, SW China. Lithos, 79: 475-489

Bai D H, Unsworth M J, Meju M A, Ma X, Teng J, Kong X, Sun Y, Sun J, Wang L, Jiang C. 2010. Crustal deformation of the eastern Tibetan plateau revealed by magnetotelluric imaging. Nat Geosci, 3: 358362

Bao X W, Sun X, Xu M, Eaton D W, Song X, Wang L, Ding Z, Mi N, Li H, Yu D, Huang Z, Wang P. 2015. Two crustal low-velocity channels beneath SE Tibet revealed by joint inversion of Rayleigh wave dispersion and receiver functions. Earth Planet Sci Lett, 415: $16-24$

Beaumont C, Jamieson R A, Nguyen M H, Lee B. 2001. Himalayan tectonics explained by extrusion of a low-viscosity crustal channel coupled to focused surface denudation. Nature, 414: 738-742

Brocher T M. 2005. Empirical relations between elastic wavespeeds and density in the Earth's crust. Bull Seismol Soc Am, 95: 20812092

Burchfiel B C, Chen Z. 2012. Tectonics of the southeastern Tibetan Plateau and its adjacent foreland. Geol Soc Am, 210, doi: 10.1130/ 2012.1210(01)

Chen H, Zhu L, Su Y. 2016. Low velocity crustal flow and crust-mantle coupling mechanism in Yunnan, SE Tibet, revealed by 3D S-wave velocity and azimuthal anisotropy. Tectonophysics, 685: 8-20

Chen J, Yang X, Xiao L, He Q. 2010. Coupling of basaltic magma evolution and lithospheric seismic structure in the Emeishan Large
Igneous Province: MELTS modeling constraints. Lithos, 119: 61-74 Chen Y, Xu Y, Xu T, Si S, Liang X, Tian X, Deng Y, Chen L, Wang P, Xu Y, Lan H, Xiao F, Li W, Zhang X, Yuan X, Badal J, Teng J. 2015. Magmatic underplating and crustal growth in the Emeishan Large Igneous Province, SW China, revealed by a passive seismic experiment. Earth Planet Sci Lett, 432: 103-114

Chen Z, Burchfiel B C, Liu Y, King R W, Royden L H, Tang W, Wang E, Zhao J, Zhang X. 2000. Global Positioning System measurements from eastern Tibet and their implications for India/Eurasia intercontinental deformation. J Geophys Res, 105: 16215-16227

Chung S L, Lee T Y, Lo C H, Wang P L, Chen C Y, Yem N T, Hoa T T, Genyao W. 1997. Intraplate extension prior to continental extrusion along the Ailao Shan-Red River shear zone. Geology, 25: 311-314

Clark M K, Royden L H. 2000. Topographic ooze: Building the eastern margin of Tibet by lower crustal flow. Geology, 28: 703-706

Deng Y, Chen Y, Wang P, Essa K S, Xu T, Liang X, Badal J. 2016. Magmatic underplating beneath the Emeishan large igneous province (South China) revealed by the COMGRA-ELIP experiment. Tectonophysics, 672-673: 16-23

Deng Y, Zhang Z, Mooney W, Badal J, Fan W, Zhong Q. 2014. Mantle origin of the Emeishan large igneous province (South China) from the analysis of residual gravity anomalies. Lithos, 204: 4-13

Fang H J, Yao H J, Zhang H, Huang Y C, van H R D. 2015. Direct inversion of surface wave dispersion for three-dimensional shallow crustal structure based on ray tracing: Methodology and application. Geophys J Int, 201: 1251-1263

Fu Y V, Gao Y, Li A, Li L, Chen A. 2017. Lithospheric structure of the southeastern margin of the Tibetan Plateau from Rayleigh wave tomography. J Geophys Res-Solid Earth, 122: 4631-4644

Fu Y V, Jia R, Han F, Chen A. 2018. SH wave structure of the crust and upper mantle in southeastern margin of the Tibetan Plateau from teleseismic Love wave tomography. Phys Earth Planet Inter, 279: $15-20$

Han F, Jia R, Fu Y V. 2017. Love wave phase velocity models of the southeastern margin of Tibetan Plateau from a dense seismic array. Tectonophysics, 712-713: 125-131

He R, Shang X, Yu C, Zhang H, Van der Hilst R D. 2014. A unified map of Moho depth and $V_{\mathrm{p}} / V_{\mathrm{s}}$ ratio of continental China by receiver function analysis. Geophys J Int, 199: 1910-1918

Hu J, Badal J, Yang H, Li G, Peng H. 2018. Comprehensive crustal structure and seismological evidence for lower crustal flow in the southeastern margin of Tibet revealed by receiver functions. Gondwana Res, 55: 42-59

Hu J, Xu X, Yang H, Wen L, Li G. 2011. S receiver function analysis of the crustal and lithospheric structures beneath eastern Tibet. Earth Planet Sci Lett, 306: 77-85 
Hu J, Yang H, Xu X, Wen L, Li G. 2012. Lithospheric structure and crust-mantle decoupling in the southeast edge of the Tibetan Plateau. Gondwana Res, 22: 1060-1067

Huang H, Yao H J, van der Hilst R D. 2010. Radial anisotropy in the crust of SE Tibet and SW China from ambient noise interferometry. Geophys Res Lett, 37: L21310

Huang H H, Xu Z J, Wu Y M, Song X, Huang B S, Nguyen L M. 2013. First local seismic tomography for Red River shear zone, northern Vietnam: Stepwise inversion employing crustal $\mathrm{P}$ and $\mathrm{Pn}$ waves. Tectonophysics, 584: 230-239

Huang Z, Wang P, Xu M, Wang L, Ding Z, Wu Y, Xu M, Mi N, Yu D, Li H. 2015. Mantle structure and dynamics beneath SE Tibet revealed by new seismic images. Earth Planet Sci Lett, 411: 100111

Kan R J, Zhang S L, Yan F T. 1977. Study on the current tectonic stress field and the characteristics of current tectonics activity in southwest China. Chin J Geophys, 20: 96-107

Kennett B L N, Engdahl E R, Buland R. 1995. Constraints on seismic velocities in the Earth from traveltimes. Geophys J Int, 122: 108124

King R W, Shen F, Clark Burchfiel B, Royden L H, Wang E, Chen Z, Liu Y, Zhang X Y, Zhao J X, Li Y. 1997. Geodetic measurement of crustal motion in southwest China. Geology, 25: 179-182

Lei J, Zhao D, Xu X, Xu Y G, Du M. 2019. Is there a big mantle wedge under eastern Tibet? Phys Earth Planet Inter, 292: 100-113

Lei J, Zhao D, Su Y. 2009. Insight into the origin of the Tengchong intraplate volcano and seismotectonics in southwest China from local and teleseismic data. J Geophys Res, 114: B05302

Lei J, Li Y, Xie F, Teng J, Zhang G, Sun C, Zha X. 2014. Pn anisotropic tomography and dynamics under eastern Tibetan plateau. J Geophys Res-Solid Earth, 119: 2174-2198

Lei J, Zhao D. 2016. Teleseismic P-wave tomography and mantle dynamics beneath Eastern Tibet. Geochem Geophys Geosyst, 17: $1861-1884$

Li C, van der Hilst R D, Meltzer A S, Engdahl E R. 2008. Subduction of the Indian lithosphere beneath the Tibetan Plateau and Burma. Earth Planet Sci Lett, 274: 157-168

Li X, Bai D, Ma X, Chen Y, Varentsov I M, Xue G, Xue S, Lozovsky I. 2019. Electrical resistivity structure of the Xiaojiang strike-slip fault system (SW China) and its tectonic implications. J Asian Earth Sci, 176: $57-67$

Liu C M, Yao H J, Yang H Y, Shen W, Fang H, Hu S, Qiao L. 2019. Direct inversion for three-dimensional shear wave speed azimuthal anisotropy based on surface wave ray tracing: Methodology and application to Yunnan, Southwest China. J Geophys Res-Solid Earth, 124: 11394-11413
Molnar P, Tapponnier P. 1975. Cenozoic Tectonics of Asia: Effects of a Continental Collision: Features of recent continental tectonics in Asia can be interpreted as results of the India-Eurasia collision. Science, 189: 419-426

Mooney W D, Ritsema J, Hwang Y K. 2012. Crustal seismicity and the earthquake catalog maximum moment magnitude (Mcmax) in stable continental regions (SCRs): Correlation with the seismic velocity of the lithosphere. Earth Planet Sci Lett, 357-358: 78-83

Peng H, Yang H, Hu J, Badal J. 2017. Three-dimensional S-velocity structure of the crust in the southeast margin of the Tibetan plateau and geodynamic implications. J Asian Earth Sci, 148: 210-222

Qiao L, Yao H, Lai Y C, Huang B S, Zhang P. 2018. Crustal structure of southwest China and northern Vietnam from ambient noise tomography: Implication for the large-scale material transport model in SE Tibet. Tectonics, 37: 1492-1506

Rawlinson N, Sambridge M. 2005. The fast marching method: An effective tool for tomographic imaging and tracking multiple phases in complex layered media. Exploration Geophys, 36: 341-350

Rowley D B. 1996. Age of initiation of collision between India and Asia: A review of stratigraphic data. Earth Planet Sci Lett, 145: 113

Royden L H, Burchfiel B C, King R W, Wang E, Chen Z, Shen F, Liu Y. 1997. Surface deformation and lower crustal flow in eastern Tibet. Science, 276: 788-790

Royden L H, Burchfiel B C, van der Hilst R D. 2008. The geological evolution of the Tibetan Plateau. Science, 321: 1054-1058

Shi Z, Wang G. 2017. Evaluation of the permeability properties of the Xiaojiang Fault Zone using hot springs and water wells. Geophys J Int, 209: 1526-1533

Sun X, Bao X, Xu M, Eaton D W, Song X, Wang L, Ding Z, Mi N, Yu D, Li H. 2014. Crustal structure beneath SE Tibet from joint analysis of receiver functions and Rayleigh wave dispersion. Geophys Res Lett, 41: 1479-1484

Tapponnier P, Peltzer G, Le Dain A Y, Armijo R, Cobbold P. 1982. Propagating extrusion tectonics in Asia: New insights from simple experiments with plasticine. Geology, 10: 611-616

Tapponnier P, Xu Z Q, Roger F, Meyer B, Arnaud N, Wittlinger G, Yang J S. 2001. Oblique stepwise rise and growth of the Tibet Plateau. Science, 294: 1671-1677

Wang E, Burchfiel B C, Royden L H, Chen L. Chen J, Li W, Chen Z. 1998. Late Cenozoic Xianshuihe-Xiaojiang, Red River, and Dali fault systems of southwestern Sichuan and central Yunnan, China. Geol Soc Amer, 327: 1-108

Wang W, Wu J, Fang L, Lai G, Cai Y. 2017. Crustal thickness and Poisson's ratio in southwest China based on data from dense seismic arrays. J Geophys Res-Solid Earth, 122: 7219-7235 
Wei W, Zhao D, Xu J. 2013. P-wave anisotropic tomography in Southeast Tibet: New insight into the lower crustal flow and seismotectonics. Phys Earth Planet Inter, 222: 47-57

Wu J, Zhang Z. 2012. Spatial distribution of seismic layer, crustal thickness, and $V_{\mathrm{p}} / V_{\mathrm{s}}$ ratio in the Permian Emeishan Mantle Plume region. Gondwana Res, 22: 127-139

Xu Y G, He B. 2007. Thick and high velocity crust in Emeishan large igneous province, SW China: Evidence for crustal growth by magmatic underplating/intraplating. In: Foulger G R, Jurdy D M, eds. Plates, plumes, and planetary processes. Geol Soc Amer, 430: $841-858$

Xu Y G, He B, Chung S L, Menzies M A, Frey F A. 2004. Geologic, geochemical, and geophysical consequences of plume involvement in the Emeishan flood-basalt province. Geology, 32: 917-920

Yang H, Peng H, Hu J. 2017. The lithospheric structure beneath southeast Tibet revealed by $\mathrm{P}$ and $\mathrm{S}$ receiver functions. J Asian Earth Sci, 138: 62-71

Yang Y, Yao H J, Wu H, Zhang P, Wang M. 2020. A new crustal shearvelocity model in Southwest China from joint seismological inversion and its implications for regional crustal dynamics. Geophys J Int, 220: 1379-1393

Yao H J. 2012. Lithospheric structure and deformation in SE Tibet revealed by ambient noise and earthquake surface wave tomography: Recent advances and perspectives. Earthq Sci, 25: 371-383

Yao H J, Beghein C, van der Hilst R D. 2008. Surface wave array tomography in SE Tibet from ambient seismic noise and two-station
analysis-II. Crustal and upper-mantle structure. Geophys J Int, 173: $205-219$

Yao H J, van der Hilst R D, de Hoop M V. 2006. Surface-wave array tomography in SE Tibet from ambient seismic noise and two-station analysis-I. Phase velocity maps. Geophys J Int, 166: 732-744

Yao H J, van der Hilst R D, Montagner J P. 2010. Heterogeneity and anisotropy of the lithosphere of SE Tibet from surface wave array tomography. J Geophys Res, 115: B12307

Zhang P Z, Shen Z, Wang M, Gan W, Bürgmann R, Molnar P, Wang Q, Niu Z, Sun J, Wu J, Sun H, You X. 2004. Continuous deformation of the Tibetan Plateau from global positioning system data. Geology, 32: 809-812

Zhang Y, Yao H, Yang H Y, Cai H T, Fang H, Xu J, Jin X, Kuo-Chen H, Liang W T, Chen K X. 2018. 3-D crustal shear-wave velocity structure of the Taiwan Strait and Fujian, SE China, revealed by ambient noise tomography. J Geophys Res-Solid Earth, 123: 80168031

Zheng X F, Yao Z X, Liang J H, Zheng J. 2010. The role played and opportunities provided by IGP DMC of China National Seismic Network in Wenchuan earthquake disaster relief and researches. Bull Seismol Soc Am, 100: 2866-2872

Zhou M F, Malpas J, Song X Y, Robinson P T, Sun M, Kennedy A K, Lesher C M, Keays R R. 2002. A temporal link between the Emeishan large igneous province (SW China) and the endGuadalupian mass extinction. Earth Planet Sci Lett, 196: 113122

(责任编委: 袁怀玉) 